\title{
Comparação entre parâmetros abióticos e a estrutura florestal de um fragmento de floresta e um reflorestamento abandonado de eucalipto (Eucalyptus saligna Smith) no parque ecológico da Klabin, Telêmaco Borba/PR
}

\author{
Comparison between abiotic parameters and the forest \\ structure of a forest fragment and an eucalyptus (Eucalyptus \\ saligna Smith) abandoned reforestation in the ecological park \\ of Klabin, Telemaco Borba/PR
}

\author{
Valéria Teodoro da Silva ${ }^{1}$; Paulo Souza Medri ${ }^{1}$; Talita Parpinelli Ferracin ${ }^{2}$; \\ Edmilson Bianchini ${ }^{3}$; José Marcelo Domingues Torezan ${ }^{3}$; José Antonio Pimenta ${ }^{3}$
}

\section{Resumo}

\begin{abstract}
A estrutura florestal tem impacto direto sobre o microclima, e é importante para a continuidade dos processos sucessionais e para o restabelecimento dos processos do ecossistema. Estudos acerca da estrutura florestal são importantes para auxiliar as ações de restauração ecológica, melhorando a sua aplicação. Visando comparar duas formações florestais, sendo uma delas um fragmento florestal secundário e a outra uma área abandonada de reflorestamento com eucalipto, neste trabalho foram avaliados alguns parâmetros abióticos, bem como a estrutura florestal das áreas. Dentre os fatores abióticos estudados estão: temperatura e umidade relativa do ar, compactação, umidade e $\mathrm{pH}$ do solo e espessura da serapilheira. Para analisar a estrutura florestal, foram avaliados: cobertura de herbáceas sobre o solo, índice de cobertura do dossel, diâmetro a altura do peito (DAP), área basal (AB) e altura das árvores de todas as espécies. Entre os parâmetros analisados, comparando-se as áreas, foram observadas que: a compactação do solo é maior na floresta secundária $(0,57 \mathrm{MPa})$ do que no reflorestamento de eucalipto (0,43 MPa); a presença de herbáceas sobre o solo é menor no reflorestamento de eucalipto $(17,96 \%)$ do que na floresta secundária (59,4\%); o índice de cobertura do dossel foi de $45,99 \%$ para o reflorestamento de eucalipto, enquanto na floresta secundária este valor foi de $61,02 \%$. No entanto, de acordo com o teste de Kolmogorov-Smirnov, a estrutura florestal não é diferente entre as áreas, já que os valores de DAP e altura não diferiram entre o calculado e o observado.

Palavras-chave: Altura. Cobertura do dossel. Diâmetro do caule. Floresta Sedundária. Regeneração. Serapilheira.
\end{abstract}

\footnotetext{
${ }^{1}$ Mestrandos do Programa de Pós Graduação em Ciências Biológicas, Laboratório de Ecologia Vegetal, Depto de Biologia Animal e Vegetal, Centro de Ciências Biológicas, Universidade Estadual de Londrina; C.P.: 6001, CEP: 86051-970 - Londrina-Pr. E-mail: valeria.teodoro@gmail.com

${ }^{2}$ Mestranda do Programa de Pós Graduação em Ciências Biológicas, Laboratório de Restauração de Ecossistemas (Labre), Depto de Biologia Animal e Vegetal, Centro de Ciências Biológicas, Universidade Estadual de Londrina; C.P.: 6001, CEP: 86051-970 Londrina-PR. Email: talitaferracin@yahoo.com.br.

${ }^{3}$ Professores do Depto. de Biologia Animal e Vegetal, Centro de Ciências Biológicas, Universidade Estadual de Londrina; C.P.: 6001, CEP: 86051-970 - Londrina-PR. Email: pimenta@uel.br.
} 


\begin{abstract}
The forest structure causes a direct impact on the microclimate, being important for the continuity of the successional processes as well as for the restoration of ecosystem processes. Studies on forest structure are important to help determine ecological restoration actions, improving its implementation. In order to compare two forest formations, being one of them a secondary forest fragment and the other one an abandoned area of eucalyptus reforestation, some abiotic parameters were evaluated in this study, as well as the forest structure of the areas. Amongst the abiotic factors studied, there are: temperature and relative air humidity, soil compaction, moisture and soil $\mathrm{pH}$ and thickness of the litter. In order to analyze the forest structure, the following items were evaluated: herbaceous cover on the soil, rate of canopy cover, the diameter at breast height (DBH), basal area (BA) and height of trees of all species. Among the parameters analyzed, comparing the areas, it was observed that: soil compaction was higher in the secondary forest $(0.57 \mathrm{MPa})$ than in the eucalyptus reforestation $(0.43 \mathrm{MPa})$; the presence of herbaceous plants on the soil occurred less in the eucalyptus reforestation (17.96\%) than in the secondary forest (59.4\%); the canopy cover index was of $45.99 \%$ for the eucalyptus reforestation, while in the secondary forest it was of $61.02 \%$, being therefore higher for the latter. Nevertheless, according to Kolmogorov Smirnov test, the forest structure is not different between the areas, since the DBH and height values were not different between what was calculated and what was observed.

Key-words: Canopy cover. Diameter. Height. Little. Regeneration. Secondary forest.
\end{abstract}

\section{Introdução}

As florestas paranaenses foram devastadas ou fragmentadas ao mesmo tempo em que as práticas agropecuárias e o extrativismo madeireiro se intensificaram no começo do século $\mathrm{XX}$ (SUGANUMA, 2005). Diante de uma paisagem danificada, houve a preocupação com sua recomposição. A partir da década de 80 , o termo restauração ecológica passou a ser mais claramente definido, e a ecologia de restauração passou a ser tratada como ciência (ENGEL; PARROTTA, 2003).

Espécies de eucalipto têm sido empregadas em larga escala em reflorestamentos e agrossilviculturas desde o início do século passado; todavia, sua expansão tem sido impulsionada a partir de meados da década de 60, com o estabelecimento de programas de incentivos fiscais, que visavam a sua utilização como matéria-prima nas indústrias, sobretudo para obter celulose e energia (LIMA, 1987). O rápido crescimento desta árvore, sua adaptação às mais variadas condições edafoclimáticas e a ampla gama de sua utilização explicam o sucesso obtido por estas espécies (GARAY et al., 2003). Contudo, o eucalipto, bem como outras espécies exóticas de crescimento rápido, são largamente utilizadas na recuperação de áreas degradadas e, neste contexto, criticadas por apresentarem pouca biodiversidade em seu sub-bosque. Atributos como biodiversidade, estrutura vegetal e funcionamento dos processos ecológicos são indispensáveis para a formação de projetos de restauração ecológica (RUIZ-JAEN; AIDE, 2005).

O solo é a característica do "habitat" que mais influencia o crescimento das plantas e, entre seus principais atributos, encontram-se: a textura, estrutura, temperatura, $\mathrm{pH}$, fertilidade, umidade e aqueles relacionados com o material de origem (PRITCHETT, 1979). Entre os atributos do solo, aqueles relacionados aos aspectos físicos, são de extrema importância, no que diz respeito ao desenvolvimento das plantas, pelo fato de que, segundo Ferreira (1993), os constituintes sólidos do solo interagem com os fluídos água e ar. Dependendo da forma como esses constituintes se associam, sua movimentação no sistema poroso é variável, 
em função do tipo de solo e/ ou, das condições de manejo às quais é submetido (RIGATTO; DEDECK; MATTOS, 2005). Normalmente não é possível antever as conseqüências de diferentes condições edáficas no desenvolvimento das plantas. Sabe-se, porém, que essas diferenças podem resultar em perda de crescimento da floresta (FROEHLICH; MILES; ROBBINS, 1985) e redução da regeneração natural, bem como prejudicar ou impedir o desenvolvimento de mudas e até provocar a morte de árvores adultas (HILDEBRAND, 1994).

Powers, Haggar e Fisher (1997) indicaram a importância da taxa de crescimento e a arquitetura das espécies plantadas na determinação da colonização por outras espécies. Silva Junior, Scarano e Souza (1995), estudando uma monocultura Eucalyptus grandis W. Hill ex Maiden, concluíram que as árvores plantadas agiram como espécies pioneiras em situações naturais, permitindo a colonização por espécies nativas. Este papel facilitador de florestas plantadas é devido a sua influência em determinadas condições, como o microclima do sub-bosque, complexidade estrutural da vegetação, desenvolvimento de serapilheira e camas de húmus durante os anos iniciais do crescimento da plantação (CARNUS et al., 2006). Segundo Kanowski, Wardell-Hohnson e Reis (2003), a biodiversidade dentro das plantações tende a aumentar com passar do tempo.

As espécies do dossel florestal, em virtude de sua estrutura e longevidade, podem exercer grande influência sobre o ambiente situado sob suas copas, e influenciam, por exemplo, o padrão de luz no sub-bosque ou sobre o solo (VÁZQUEZ-YANEZ; OROSCO-SEGOVIA, 1990; FACELLI; PICKETT, 1991; GANDOLFI, 2000). Conseqüentemente, elas afetam a temperatura superficial do solo (MOLOFSKY; AUGSPURGER, 1992) e a germinação e o estabelecimento de espécies (GUARIGUATA; OSTERTAG, 2001).

Considerando que a estrutura florestal tem um impacto direto sobre o microclima, e é importante fator para a continuidade do processo sucessional e para o restabelecimento dos processos do ecossistema, sugere-se que mudanças na estrutura florestal dos reflorestamentos devem conduzi-los a uma maior similaridade com florestas naturais (ENGEL; PARROTTA, 2003). Do mesmo modo, mudanças nos processos do ecossistema, como, por exemplo, o ritmo de aumento da biomassa e necromassa, podem indicar uma recuperação florestal mais rápida ou mais lenta (SUGANUMA, 2008).

Com o objetivo de comparar um fragmento florestal secundário e uma área abandonada de reflorestamento com eucalipto, levantou-se nesse estudo duas hipóteses: (a) existe diferença entre a estrutura florestal do fragmento secundário e o reflorestamento de eucalipto; (b) as condições abióticas como microclima e edáficas são diferentes entre essas duas formações vegetais.

\section{Material e métodos}

Sitios de estudo

O parque ecológico da Empresa de Papel e Celulose Klabin S.A. fica no município de Telêmaco Borba, na região centro-leste do estado do Paraná, entre o limite do rio Tibagi e a fazenda Monte Alegre, nas coordenadas $24^{\circ} 17^{\prime} \mathrm{S} 50^{\circ} 35^{\prime} \mathrm{W}$ a aproximadamente 815 metros acima do nível do mar. Tem clima classificado como uma transição entre $\mathrm{Cfa}$ e $\mathrm{Cfb}$, de acordo com os tipos climáticos de Köppen, sendo descritos como subtropicais úmidos, com calor moderado até verões muito quentes e úmidos e invernos frios; a temperatura média do mês mais frio é de $16,3^{\circ} \mathrm{C}$ e a temperatura média do mês mais quente é de $23,2^{\circ} \mathrm{C}$. As chuvas são regulares, sendo que as médias pluviométricas anuais variam de 1478 a $1700 \mathrm{~mm}$ (TREWARTHA; HORN, 1980; BARBOSA et al., 2007).

O parque é uma área particular com 11.196 ha pertencente à Empresa Klabin, sendo que deste total, segundo Fávaro et al. (2006) e Barbosa 
et al. (2007), 7.883 ha são ocupados por blocos dispersos de remanescentes de floresta secundária, interligados por diversos cursos d'água e galerias florestais, sendo que o restante é ocupado com reflorestamentos de Araucaria angustifolia (Bertol.) O. Kuntze, Eucalyptus spp. e Pinus spp.

A floresta secundária do parque da Klabin pode ser considerada como uma área de transição, visto que apresenta aspectos tanto da Floresta Estacional Semidecidual quanto da Floresta Ombrófila Mista (FÁVARO et al. 2006). As áreas de cobertura florestal secundária ocorrem em blocos dispersos em toda parte da propriedade e são interligadas por florestas ciliares (BARBOSA et al., 2007, MEDRI et al., 2009). O fragmento florestal delimitado para este estudo encontra-se dentro do Parque Ecológico, enquanto que o reflorestamento com plantas do gênero Eucalyptus localiza-se numa área adjacente ao parque, mas situado em meio à matriz florestal (BARBOSA et al., 2007).

Segundo dados do cadastro florestal da Klabin S.A., a plantação de eucalipto estudada é de junho de 1987, plantio este feito por estaquia de plantas de Eucalyptus saligna Smith. Anteriormente ao plantio, a área escolhida teve o remanescente da vegetação queimado, seguido de rebaixamentos de tocos e gradagem. Em setembro e dezembro de 1987 e abril de 1988 foram feitos manejos manuais (limpeza com enxada) na plantação, sendo que em agosto e dezembro de 1997 e dezembro de 1998 foram feitos manejos mecânicos na área, utilizando-se de capina química. Em dezembro de 1993 foi feito um desbaste no local, a partir do qual foram extraídos $682 \mathrm{~m}^{3}$ de madeira. O mesmo aconteceu em junho de 1997, contudo o volume extraído foi de $750 \mathrm{~m}^{3}$.

\section{Coleta de dados}

Para o estudo foram delimitadas parcelas de 10x10m em áreas de aparência homogênea, ao longo de transectos, alocando-se quatro parcelas em cada sítio; quatro no reflorestamento com eucalipto e quatro no fragmento florestal, totalizando oito parcelas, distribuídas nas áreas de estudo. Visando facilitar a coleta de alguns dados, cada parcela foi dividida visualmente em quatro quadrantes de $5 \times 5 \mathrm{~m}$. Os dados abióticos coletados foram:

Temperatura $\left({ }^{\circ} \mathrm{C}\right)$ e umidade relativa do ar (\%): foram registradas por coletores de dados eletrônicos automáticos (Data-logger), instalados, aleatoriamente, em 3 locais de cada área. Os aparelhos, previamente identificados, foram configurados para coletar dados de uma em uma hora a partir das 18:00h do dia 10/03/2008 até as 10:00h do dia 14/03/2008.

Compactação do solo: foi avaliada uma medida de compactação por quadrante da parcela (4 em cada parcela) com o uso de um penetrômetro portátil que faz a medida da força, em $\mathrm{MPa}$, necessária à penetração de uma ponta de prova no solo.

Umidade e $\mathrm{pH}$ do solo: mensurados com aparelho próprio, fazendo-se quatro medidas por parcela, uma em cada quadrante.

Espessura da serapilheira: foi mensurada com fita métrica em seis pontos regularmente distribuídos dentro de cada parcela utilizando-se de cortes verticais do solo (MEDRI et al., 2009). O método consiste em cortar a serapilheira, em um único movimento, com uma ferramenta cortante que penetra no solo. Sem retirar a ferramenta, empurra-a para um dos lados e expõe o perfil aberto pelo corte. Esse método permite medir, em centímetros, a altura da necromassa.

No que se refere à estrutura florestal (parâmetros bióticos), foram mensurados:

Cobertura de herbáceas: em cada parcela foi estimada, visualmente, em termos percentuais, a cobertura do estrato herbáceo dos quadrantes.

Índice de cobertura do dossel: avaliado conforme o índice de abertura florestal, o qual foi mensurado em quatro pontos da parcela, com o auxílio de um densiômetro esférico. A partir deste dado, calculou-se a porcentagem total da cobertura 
do dossel.

Altura total das árvores: estimada visualmente, sempre pela mesma pessoa para diminuir o erro, tomando-se como referência um objeto de medida conhecida.

Diâmetro a Altura do Solo (DAS) e Área Basal (AB): as medidas foram realizadas com auxílio de fita métrica em todos os indivíduos com Diâmetro aAltura do Peito (DAP) maior ou igual a $2,5 \mathrm{~cm}$. Para os cálculos de área basal, foram tomadas medidas de DAS a $5 \mathrm{~cm}$ do solo, enquanto que, para o DAP, a $130 \mathrm{~cm}$ do solo. Posteriormente, para os dados de DAS, foram feitas duas análises: uma considerando todos os indivíduos amostrados, ou seja, com DAP acima de 2,5 cm e outra desconsiderando indivíduos com DAS acima de $108 \mathrm{~cm}$, em ambas as áreas estudadas. Essa última análise foi feita para verificar a influência da $\mathrm{AB}$ das árvores maiores (plantadas) sobre a $\mathrm{AB}$ dos regenerantes.

A

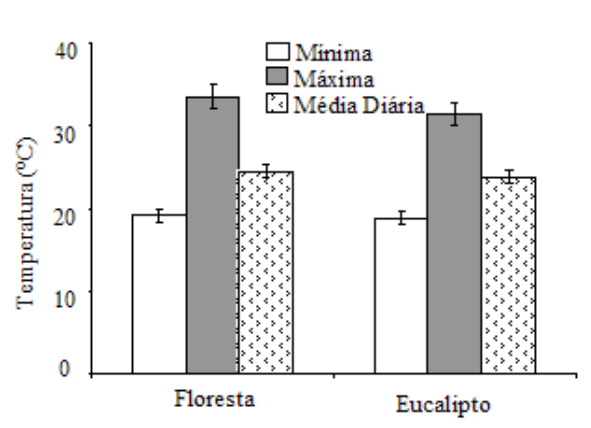

Os dados foram analisados através de comparações entre médias e erro padrão de cada parâmetro avaliado. Foi realizado o teste de Kolmogorov-Smirnov para averiguar a existência de diferenças entre as estruturas de tamanho dos indivíduos de cada local comparado (SIEGEL, 1975; ZAR, 1984).

\section{Resultados}

Não houve diferenças nos valores de temperatura (Figuras 1A e 1B) e umidade relativa do ar (Figura 1C) entre a área de reflorestamento com eucalipto e o fragmento de floresta nativa.

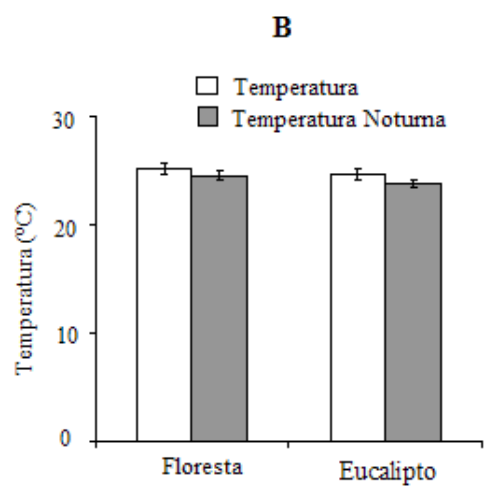

C

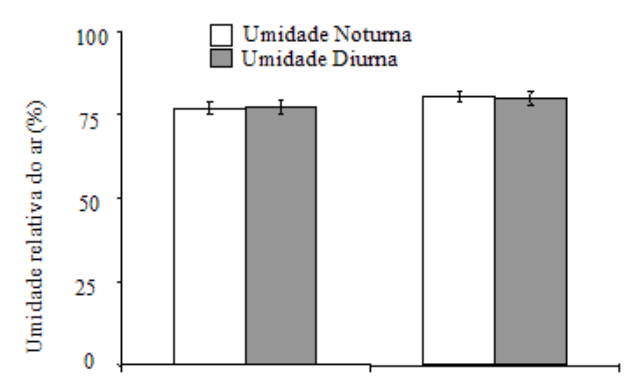

Figura 1. Temperatura máxima, mínima e média diária (A); temperatura diurna e noturna (B); umidade noturna e diurna (C) na floresta secundária e no reflorestamento abandonado de eucalipto em Telêmaco Borba, PR. Os traços verticais acima das barras indicam o erro padrão. 
Quando comparado com o solo do reflorestamento de eucalipto abandonado, a compactação foi maior no solo da floresta secundária (Figura 2). Não foram observadas diferenças no $\mathrm{pH}$ do solo entre as áreas (Figura 3A), o mesmo ocorrendo com a espessura da serapilheira (Figura 3B). Observou-se maior quantidade de herbáceas no sub-bosque do fragmento de floresta (Figura 4A). Esse fragmento também apresentou maior porcentagem de cobertura do dossel (Figura 4B). O fragmento florestal secundário tem o maior número de indivíduos nas classes de menores tamanhos. Já no reflorestamento, a quantidade de indivíduos por classe é menor do que na floresta, mas segue o mesmo padrão de J-invertido (Figura. 5A e 5B).

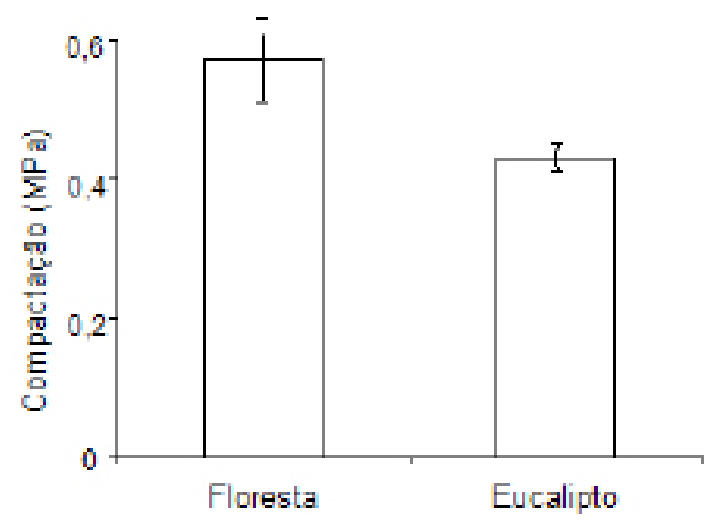

Figura 2. Compactação do solo $(\mathrm{MPa})$ na floresta secundária e no reflorestamento abandonado de eucalipto em Telêmaco Borba, PR. Os traços verticais acima das barras indicam o erro padrão.

A

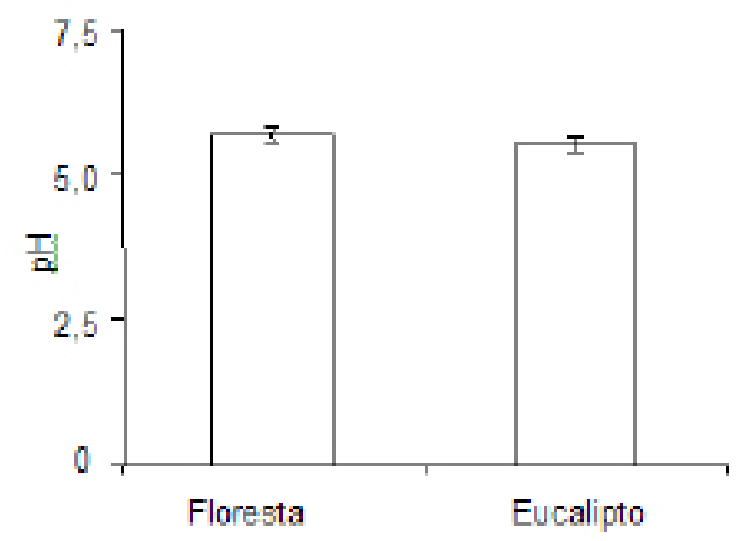

B

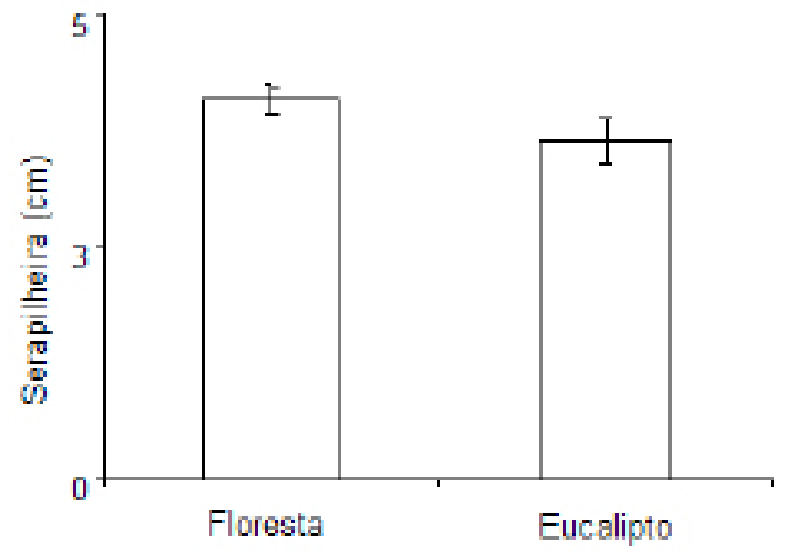

Figura 3. pH do solo (A) e espessura da serapilheira (B) na floresta secundária e no reflorestamento abandonado de eucalipto em Telêmaco Borba, PR. Os traços verticais acima das barras indicam o erro padrão. 

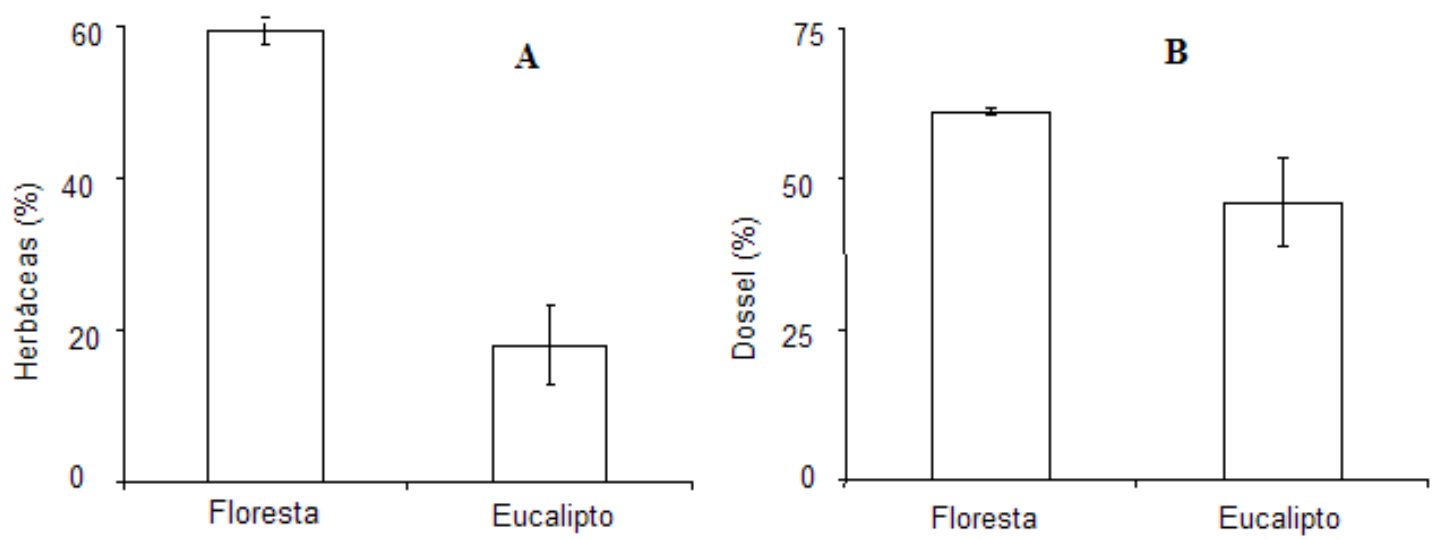

Figura 4. Presença de herbáceas no sub-bosque (A) e índice de cobertura do dossel (B) na floresta secundária e no reflorestamento abandonado de eucalipto em Telêmaco Borba, PR. Os traços verticais acima das barras indicam o erro padrão.
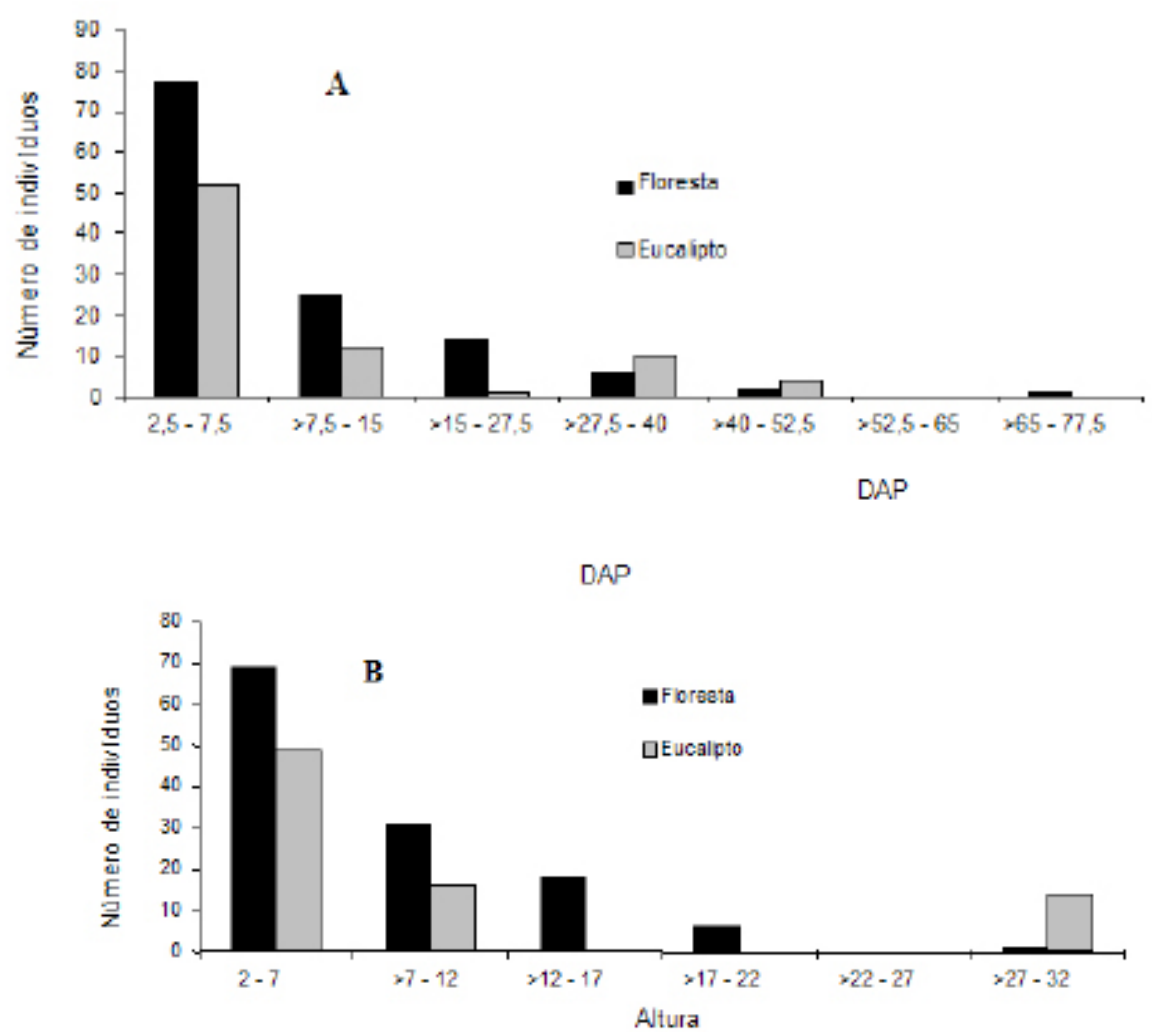

Figura 5. Número de indivíduos de diferentes classes de diâmetro a altura do peito (DAP) (A) e de altura total (B) da área de floresta secundária e do reflorestamento abandonado de eucalipto em Telêmaco Borba, PR.

Tanto para a estrutura de tamanho em diâmetro quanto em altura dos indivíduos das duas áreas, não foram observadas diferenças na estrutura pelo teste de Kolmogorov (Tabela 1). 
Tabela 1. - Comparação da estrutura de tamanho dos indivíduos de uma floresta secundária e de um reflorestamento a bandonado de eucalipto amostrados em Telêmaco Borba, PR. D (obs) - valor de D observado; D (calc) - valor de D calculado pelo Teste de Kolmogorov-Smirnov com nível de significância de 0,05.

\begin{tabular}{lcc}
\hline & Diâmetro & Altura \\
D (obs.) & 0,11 & 0,17 \\
D (calc.) & 0,2 & 0,2 \\
\hline
\end{tabular}

Foram amostrados 125 indivíduos arbóreos no fragmento de floresta nativa e 79 indivíduos no reflorestamento com eucalipto, o que representa uma densidade média de 3125 e 1975 indivíduos por hectare, respectivamente.

Quanto à comparação da área basal na floresta secundária e no reflorestamento, observa-se que a floresta apresentou maior área basal em comparação com o fragmento de reflorestamento com eucalipto (Figura 6A). A área basal é maior na floresta secundária, mesmo retirando-se as plantas com DAS superior a $108 \mathrm{~cm}$ (Figura 6B).
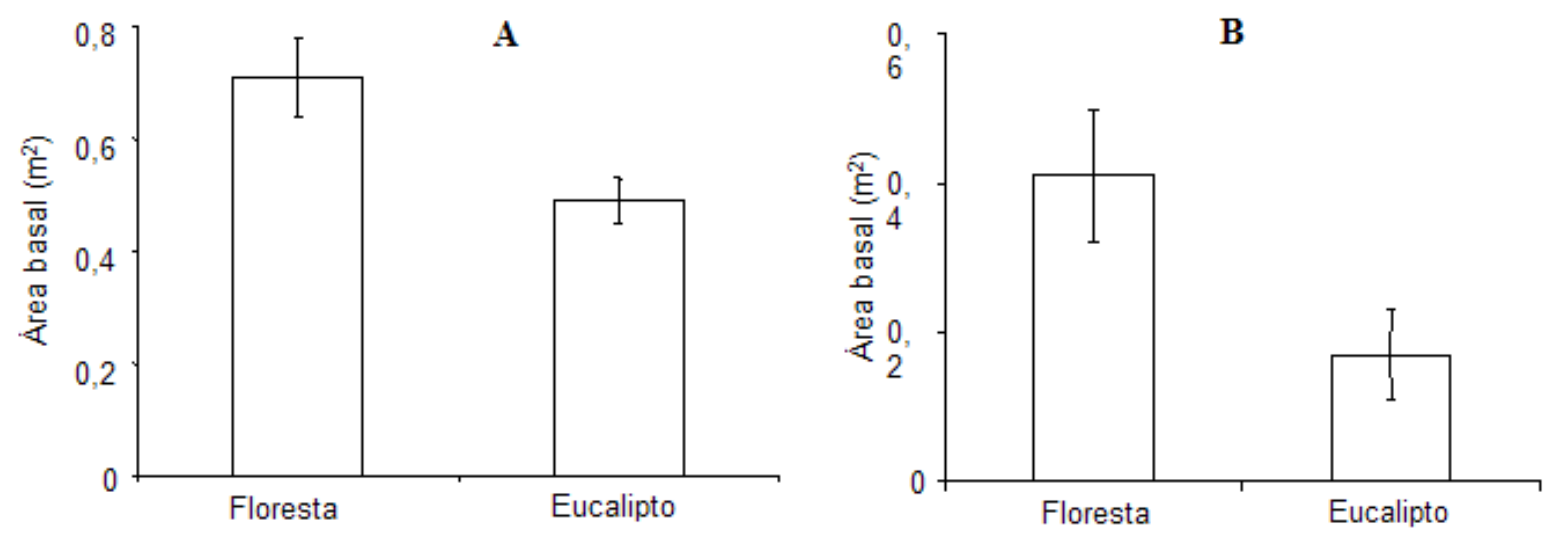

Figura 6. Áreas basais $\left(\mathrm{m}^{2}\right)$ amostradas em fragmento de floresta secundária e em reflorestamento abandonado de eucalipto em Telêmaco Borba, PR. (A) todas as plantas amostradas e (B) retirando-se da amostragem as árvores acima de $108 \mathrm{~cm}$ de DAS.

\section{Discussão}

Considerando que a umidade relativa do ar é a relação entre a quantidade de água existente no ar (umidade absoluta) e a quantidade máxima que poderia haver na mesma temperatura (ponto de saturação). Considerando também que a umidade é aumentada com a chuva, devido à evaporação posterior (AYOADE, 2002), então, pode-se afirmar que o período de elevada pluviosidade (que coincidiu com o período de coleta) interferiu nos dados de umidade relativa do ar coletados pelos dispositivos Datalogger, uma vez que estes valores foram constantes entre as duas áreas e em todos os períodos do dia. Além disso, a falta de variação da temperatura em ambas as áreas contribuiu para que a umidade relativa permanecesse inalterada. Já a umidade relativa do ar de acordo com a temperatura, presença ou não de vegetação, rios e represas, e a quantidade de água que o ar absorve antes de atingir a saturação depende da temperatura e aumenta 
progressivamente com ela (AYOADE, 2002). Sendo assim, quanto maior a temperatura do ar, maior sua capacidade de conter umidade.

Thébaud e Strasberg (1997) e Brooks e KylerSnowman (2007) ressaltaram que a estrutura florestal influencia diretamente a temperatura, a amplitude térmica e a umidade relativa do ar, visto que uma estrutura mais complexa comum em fragmentos florestais, provavelmente possibilita uma menor variação de temperatura do que em reflorestamentos. Spurr (1964) afirma que a estrutura do dossel determina a temperatura do interior de reflorestamentos ou florestas, já que, é a copa que possibilita a penetração da radiação solar até o subbosque e o aquecimento das camadas inferiores, assim como é também a responsável em diminuir as perdas de calor para a atmosfera. De acordo com o mesmo autor, a pouca densidade de copas ou árvores sem folhas, como no caso de árvores decíduas durante a estação hibernal, provoca uma redução na movimentação do ar, enquanto a radiação solar penetra no dossel. Sob tais condições, a temperatura média diária tende a ser mais elevada dentro da floresta. Quando as árvores estão completamente revestidas de folhas, as temperaturas extremas tendem a ser mais baixas dentro da floresta e a diminuição da radiação pode ter como resultante uma temperatura média anual mais baixa (SPURR, 1964). Segundo Reich (1995) em ambientes mais abertos, como é o caso verificado no reflorestamento com eucalipto, a umidade relativa do ar tende a ser menor e a transpiração maior.

Sendo assim, as variações dos dados de umidade e temperatura nestas áreas de estudo não seguiram o padrão esperado, principalmente porque a análise do índice de cobertura do dossel mostra que a floresta tem um dossel mais fechado em comparação com o reflorestamento.

O índice de cobertura do dossel analisado para as duas áreas foi semelhante a outros estudos, em que o reflorestamento apresenta dossel mais aberto em comparação com a floresta. A proporção de abertura no dossel de uma floresta pode ser influenciada por muitos aspectos de sua estrutura, como o arranjo espacial das plantas, a arquitetura das copas e a área foliar (BIANCHINI; PIMENTA; SANTOS, 2001). Esse arranjo também reflete o resultado complexo e dinâmico das interações fisiológicas e evolutivas entre a vegetação e o ambiente (SCHUMACHER; POGGIANI, 1993). É a arquitetura da copa das árvores que afeta a produtividade primária do ecossistema como um todo e regula também a luz, temperatura, vento e umidade sob o dossel e altura do piso florestal (SCHUMACHER; POGGIANI, 1993). Alguns reflorestamentos tendem a apresentar maiores porcentagens de abertura de dossel (TRICHON; WALTER; LAUMONIER, 1998) e isso também ocorre com as florestas em estádios sucessionais iniciais, em que não existem três estratos de vegetação bem estabelecidos, e em áreas que sofreram perturbações recentes. O sub-bosque de florestas tropicais, em geral, apresenta uma abertura de dossel entre 0,2 a 6,5\% (MONTTGOMERY; CHAZDON, 2002). A presença de áreas mais abertas permite uma disponibilização de recursos apropriados para promover o crescimento e germinação de sementes de plantas arbóreas ou arbustivas, podendo influenciar na composição e diversidade de espécies dessas florestas (WIRTH; WEBER; RYEL, 2001). Desse modo, essa diversidade de locais com maior ou menor luminosidade gera oportunidades distintas para as espécies que habitam o sub-bosque (GARCIA et al., 2007).

Contudo, considerando a menor percentagem de herbáceas no reflorestamento, pode-se sugerir que a abertura do dossel não está facilitando o estabelecimento de herbáceas no sub-bosque. Garcia et al. (2007) e Meira-Neto, Martins e Souza (2004) apresentam estudos que sugerem que a luminosidade não exerce um papel limitante na distribuição espacial das herbáceas na área de estudo, uma vez que, tanto no menor como no maior nível de luz abaixo do dossel, foi observada uma densidade similar de plantas. De acordo com Aubert e Oliveira 
Filho (1994), a regeneração natural dos sub-bosques pode apresentar estreita dependência de formações florestais vizinhas, bem como a ecologia da dispersão de cada espécie regenerante, os efeitos de borda e de clareiras, práticas de manejo, vizinhança de pastagens, sentido dos ventos e possíveis efeitos alelopáticos. Além disso, a serapilheira do reflorestamento de eucalipto possui os ritidomas das árvores apresentando-se como barreira mecânica, de modo a prejudicar o estabelecimento de novas plantas.

Mesmo com os ritidomas na área de reflorestamento com eucalipto, as médias da espessura de serapilheira entre as áreas não foram significativamente diferentes, Figueiredo Filho et al. (2003) descrevem que diferentes ecossistemas florestais depositam diferentes quantidades de serapilheira. De acordo com Haag (1985), essas diferenças advêm do ciclo biológico, das condições climáticas, entre outros fatores. Bray e Gorham (1964) afirmam que sob condições climáticas adequadas, quanto maior a disponibilidade de nutrientes de um ecossistema, mais elevada é a absorção de nutrientes e maior é a produção primária líquida de biomassa; positivamente correlacionado, maior também é a deposição de resíduos vegetais sobre o terreno. A devolução destes resíduos ao solo é fundamental para manutenção das comunidades florestais, uma vez que a produção e a decomposição de serapilheira são processos fundamentais à manutenção da ciclagem de nutrientes (LEITÃO FILHO, 1993). Neste processo de decomposição, os valores de $\mathrm{pH}$ do solo podem ser afetados. Poggiani et al. (1987) afirma que quando a velocidade de decomposição da serapilheira é lenta, ocorre formação de ácidos e conseqüente abaixamento do $\mathrm{pH}$ do solo. Chaer (2001) apud Gatto et al. (2003), ao determinar os índices de qualidade do solo em povoamentos de eucalipto submetidos a diferentes intensidades de manejo, comparados ao povoamento de floresta, encontrou índices de qualidade do solo mais elevados e semelhantes aos da mata para os povoamentos de eucalipto submetidos a manejos menos intensivos. Dessa maneira, os valores de $\mathrm{pH}$ do solo nas áreas estudadas podem estar relacionados à velocidade de decomposição da serapilheira depositada.

Além disso, Gonçalves (1995), ao interpretar dados acerca da distribuição de raízes em perfis de solo de diversos povoamentos de Eucalyptus grandis, sugeriu que a presença de serapilheira sobre o solo estimula o crescimento de raízes finas nas camadas superficiais, graças ao provimento de um microambiente propício ao crescimento de raízes: ausência de radiação solar direta, redução das variações de amplitudes térmicas e hídricas das camadas superficiais do solo e aumento da disponibilidade de nutrientes. De acordo com Laclau et al. (2004), a proliferação de raízes finas na camada da superfície orgânica do solo no ecossistema florestal é vista como uma estratégia para adquirir nutrientes em solos inférteis, nos quais há limitação de nutrientes. Isso é muito importante em floresta tropical, onde a maioria dos solos são altamente intemperizados e a camada de raízes, freqüentemente, desenvolve-se dentro da camada orgânica para captura, ao longo do ano, de nutrientes produzidos pela decomposição da matéria orgânica (FREITAS; BARROSO; CARNEIRO, 2008). Laclau et al. (2001) demonstraram elevada heterogeneidade na distribuição espacial de raízes de espécies de Eucalyptus spp. e a redução de sua densidade com o aumento da profundidade. De acordo com Gonçalves (1995), o crescimento de raízes promove certo revolvimento do solo adjacente, e influencia a compactação dele, e isso pode explicar a menor compactação no reflorestamento. Embora os valores de compactação do solo tenham sido estatisticamente diferentes entre as áreas analisadas, segundo a Soil Survey Division Staff (1993), os níveis de compactação apresentados pela floresta secundária e pelo reflorestamento podem ser classificadas como baixas. Os solos são classificados de alta resistência quando os valores para compactação são maiores que 2,0 MPa (MATERECHERA; DEXTER; ALSTON, 1991). 
Para a estrutura de tamanho em forma de "J-invertido" encontrada em ambas as áreas de estudo, Scolforo, Pulz e Mello (1998) afirmam que a maior concentração de indivíduos nas primeiras classes de diâmetro pode caracterizar uma comunidade estoque (abundância de indivíduos no componente da regeneração natural), o que é um padrão em florestas tropicais estáveis com idade e composição de espécies variadas. Na medida em que aumenta o tamanho da classe, a frequência diminui até atingir o seu menor índice na maior classe diamétrica, caracterizando uma curva do tipo exponencial negativa ou denominada como "J-invertido"(SCOLFORO; PULZ; MELLO, 1998). O modelo de distribuição "J-invertido" sugere que as populações que compõem uma comunidade são estáveis e autoregenerativas, e existe um balanço entre mortalidade e o recrutamento dos indivíduos (PEREIRA-SILVA, 2004). Webb, Tracey e Willins (1972) verificaram que padrões de crescimento inicial lento resultam em distribuições na forma de "J-invertido", uma vez que os indivíduos permanecem na mesma classe diamétrica por longo período de tempo. Em populações que apresentam distribuição balanceada de diâmetros, a redução do número de indivíduos de uma classe de diâmetros para outra seria uma razão constante, ao contrário, quando a distribuição fosse não balanceada, essa redução seria diretamente proporcional ao diâmetro (LEAK, 1964). Em florestas nativas, quando a razão do coeficiente " $q$ " de Liocourt é constante (o qual é obtido pela divisão do número de indivíduos de uma classe de diâmetro pelo número de indivíduos da classe anterior) significa que existe equilíbrio entre mortalidade e crescimento, ou seja, um balanceamento. Quando isso ocorre por um longo período, pode-se dizer que a estrutura da floresta está balanceada ou estabilizada e nesse caso ocorre um número proporcional de árvores em cada classe diamétrica (OSMASTON, 1968). Entretanto, Harper (1977) atenta que, na prática, a maioria das florestas irregulares não apresenta distribuição balanceada, mas tem uma tendência a convergir para esse padrão. Segundo Rubin, Manion e Faber-Langendoen (2005) o padrão "J-invertido", encontrado na estrutura de tamanho dos indivíduos da floresta secundária e do reflorestamento, indica florestas maduras ou que caminham para o amadurecimento. De acordo com o analisado pelo teste de Kolmogorov-Smirnov, os valores de DAP e altura, não diferiram entre o calculado e o observado, portanto, a hipótese de que as estruturas florestais das áreas estudadas são diferentes entre si, deve ser rejeitada. Pereira-Silva (2004) afirma que o modelo baseado na movimentação dos diâmetros, ou seja, no crescimento diamétrico, pode ser utilizado como forma de avaliação da estrutura de tamanho da comunidade, indicando que a situação atual da distribuição diamétrica ainda evidencia alterações conseqüentes das atividades de manejo.

Embora a floresta tenha menor número de indivíduos com altos valores de DAS, estes indivíduos apresentam diâmetros consideráveis, que ultrapassam os valores mensurados no reflorestamento. Quando as plantas (de ambas as áreas) com DAS superior a $108 \mathrm{~cm}$ são retiradas dos cálculos, a área basal continua maior na floresta secundária, porque a quantidade de indivíduos por parcela é maior nesta área. De acordo com Uhl e Murphy (1981) e Parthasarathy (1999) a densidade e a área basal médias das florestas tropicais variam muito com as condições de solos, água e luz, bem como entre estádios de regeneração. Os mesmos autores afirmam que as florestas maduras apresentam maior número de árvores com áreas basais grandes, enquanto aquelas em estádios mais iniciais de regeneração formam grandes adensamentos de árvores finas. Segundo Amaral et al. (1996), incrementos de área basal relacionam-se à idade das áreas estudadas e fertilidade do solo.

\section{Conclusão}

No que se refere à estrutura florestal da floresta secundária e do reflorestamento com eucalipto, a presença de herbáceas e índice de cobertura do 
dossel foram os únicos parâmetros que apresentaram diferenças significativas. De acordo com os demais parâmetros analisados, os quais não apresentaram diferenças estatisticamente diferentes entre as áreas estudadas, o reflorestamento abandonado caminha para equiparar-se à floresta secundária.

Quanto aos parâmetros abióticos comparados entre as áreas, verificou-se que apenas a compactação do solo apresentou diferenças significativas.

\section{Agradecimentos}

Ao professor Dr. José Lopes pela colaboração nas coletas de dados em campo. À empresa de Papel e Celulose Klabin S.A pelo apoio logístico. Á CAPES e ao Programa de Pós-Graduação em Ciências Biológicas da UEL pelo apoio financeiro.

\section{Referências bibliográficas}

AMARAL, S.; SOARES, J. V.; ALVES, D. S.; MELLO, E. M. K.; ALMEIDA, S. A. S.; SILVA, O. F.; SILVEIRA, A. M. Relações entre índice de área foliar (LAI), área basal e índice de vegetação (NDVI) em relação a diferentes estágios de crescimento secundário na Floresta Amazônica em Rondônia. In: ANAIS DO VIII SIMPÓSIO BRASILEIRO DE SENSORIAMENTO REMOTO, 8., 1996, Salvador: INPE, 1996. p. 485-489.

AUBERT, E. E.; OLIVEIRA FILHO, A. T. Análise multivariada da estrutura fitossociológica do sub-bosque de plantios experimentais de Eucalyptus spp. e Pinus spp. em Lavras, MG. Revista Árvore, Viçosa, v. 18, n. 3, p.194-214, 1994.

AYOADE, J. O. Introdução à climatologia para os trópicos. 8. ed. Rio de Janeiro: Bertrand Brasil. 2002. $332 \mathrm{p}$.

BARBOSA, C. E.; BENATO, A. T.; CAVALHEIRO, A. L.; TOREZAN, J. M. D. Diversity of Regenerating Plants in Reforestations with Araucaria angustifolia (Bertol.) O. Kuntze of 12, 22, 35, and 43 Years of Age in Parana' State, Brazil. Restoration Ecology, Malden, v. 17, n. 1, p. 60-67, 2007.

BIANCHINI, E.; PIMENTA, J. A.; SANTOS, F. A. M. Spatial and Temporal Variation in the Canopy Cover in a Tropical Semi-Deciduous Forest. Brazilian Archives of Biology and Technology, Curitiba, v. 44, n. 3, p. 269-276, 2001.
BRAY, J. R.; GORHAM, E. Litter production in the forests of the world. Advances in Ecological Research, London, v. 2, p. 101-157, 1964.

BROOKS, R. T.; KYLER-SNOWMAN, T. D. Forest floor temperature and relative humidity following timber harvesting in southern New England, USA. Forest Ecology and Management, v. 254, n. 2008, p. 65-73, 2007.

CARNUS, J.; PARROTTA, J. A.; BROCKERHOFF, E.; ARBEZ, M.; JACTEL, H.; KREMER, A.; LAMB, D.; O'HARA, K.; WALTERS, B. Planted forests and biodiversity. Journal of Forestry, Washington, v. 104, n. 2, p. 65-77, 2006.

ENGEL, V. L.; PARROTTA, J. A. Definindo a restauração ecológica: tendências e perspectivas mundiais. In: KAGEYAMA, P. Y.; OLIVEIRA, R. E.; MORAES, L. F. D.; ENGEL, V. L.; GANDARA, F. B. (Eds.). Restauração Ecológica de Ecossistemas Naturais. Botucatu: Fundação de Estudos e Pesquisas Agrícolas Florestais, 2003. p. $1-26$.

FACELLI, J. M.; PICKETT, S. T. A. Plant litter: light interception and effects on an old-field plant community. Ecology, Washington, v. 72, n. 3, p. 1024-1031, 1991.

FÁVARO,F.L.;ANJOS, L.; LOPES, E. V.; MENDONÇA, L. B.; VOLPATO, G. H. Efeito do gradiente altidudinal/ latitudinal sobre espécies de aves florestais da família Furnariidae na Bacia do Rio Tibagi - PR/Brasil. Revista Brasileira de Zoologia, São Paulo, v. 23, n. 1, p. 261-266, 2006.

FERREIRA, M. M. Física do solo. Lavras: ESAL/ FAEPE, 1993. $63 \mathrm{p}$.

FIGUEIREDO FILHO, A.; MORAES, G. F.; SCHAAF, L. B.; FIGUEIREDO, D. J. Avaliação Estacional da Deposição de Serapilheira em uma Floresta Ombrófila Mista Localizada no Sul do Estado do Paraná. Ciência Florestal, Santa Maria, v. 13, n. 1, p. 11-18, 2003.

FREITAS, T. A. S.; BARROSO, D. G.; CARNEIRO, J. G. A. Dinâmica de raízes de espécies arbóreas: visão da literatura. Ciência Florestal, Santa Maria, v. 18, n. 1, p. 133-142, 2008.

FROEHLICH, H. A.; MILES, D. W. R.; ROBBINS, R. W. Soil bulk density recovery on compacted skid trails in Central Idaho. Soil Science Society America Journal, Madison, v. 49, n. x, p. 1015-1017, 1985.

GANDOLFI, S. História natural de uma Floresta Semidecidual no Município de Campinas (São Paulo, Brasil). 2000. Tese (Doutorado) - Instituto de Biologia, Universidade Estadual de Campinas, Campinas, 2000. 
GARAY, I.; KINDEL A.; CARNEIRO R.; FRANCO, A. A.; BARROS, E.; ABBADIE L. Comparação da matéria orgânica e de outros atributos do solo entre plantações de Acacia mangium e Eucalyptus grandis. Revista Brasileira Ciência do Solo, Campinas, v. 27, n. 4, p. 705712, 2003.

GARCIA, L. C.; REZENDE, M. Q.; PIMENTA, M. A.; MACHADO, R. M.; LEMOS-FILHO, J. P. Heterogeneidade do dossel e quantidade de luz no recrutamento do sub-bosque de uma mata ciliar no Alto São Francisco, Minas Gerais: análise através de fotos hemisféricas. Revista Brasileira de Biociências, Porto Alegre, v. 5, n. 2, p. 99-101, 2007.

GATTO, A.; BARROS, N. F.; NOVAIS, R. F.; COSTA, L. M.; NEVES, J. C. L. Efeito do método de preparo do solo em área de reforma, nas suas características, na composição mineral e na produtividade de plantações de Eucalyptus grandis. Revista Árvore, Viçosa, v. 5, n, 27, p. 635-646, 2003.

GONÇALVES, J. L. M. Efeitos do cultivo mínimo sobre a fertilidade do solo e ciclagem de nutrientes. In: SEMINÁRIO SOBRE CULTIVO MÍNIMO DO SOLO EM FLORESTAS, 1., 1995, Curitiba. Anais... Curitiba: CNPFloresta/IPEF/UNESP/SIF/FUPEF, 1995. p.43-60.

GUARIGUATA, M. R.; OSTERTAG, R. Neotropical secondary forest succession: changes in structural and functional characteristics. Forest Ecology and Management, Amsterdam, v. 148, n. 1/3, p.185-206, 2001.

HAAG, H. P. Ciclagem de nutrientes em florestas tropicais. Campinas: Fundação Cargill, 1985. 144 p.

HARPER, J. L. Population biology of plants. New York : Academic Press, 1977.

HILDEBRAND, E. E. Medium to root growth. In: IUFRO/ ECE INTERACTIVE WORKSHOP AND SEMINAR: SOIL, TREE, MACHINE INTERACTIONS, 1994, Germany. Proceedings... Germany, 1994. p. 281-289.

KANOWSKI, C. P. J.; WARDELL-JOHNSON, G. W.; REIS, T. Development of forest structure on cleared rainforest land in eastern Australia under different styles of reforestation. Forest Ecology and Management, Amsterdam, v. 183, n. 3, p. 265-280, 2003.

LACLAU, J. P.; ARNAUD, M.; BOUILLET, J. P.; RANGER, J. Spatial distribution of Eucapyptus roots in a deep sandy soil in the Congo: relationships with the ability of the stand to take up water and nutrients. Tree Physiology, Oxford, v. 21, n. 2/3, p.129-136, 2001.

LACLAU, J. P.; TOUTAIN, F.; M'BOU, A. T.; ARNAUD, M.; JOFFRE, R.; RANGER, J. The function of the superficial root mat in the biogeochemical cycles of nutrients in Congolese Eucalyptus plantations. Annals of Botany, Oxford, v. 93, n. 3, p. 249-261, 2004.

LEAK, W. B. An expression of diameter distribution for unbalanced, uneven-aged stands and forests. Forest Science, Paris, v. 10, n. 1, p. 39-50, 1964.

LEITÃO-FILHO, H. F. Ecologia da Mata Atlântica em Cubatão (SP). São Paulo: EDUNESP/EDUNICAMP, 1993.

LIMA, W. P. O reflorestamento com eucalipto e seus impactos ambientais. São Paulo: Artpress, 1987. 114 p.

MATERECHERA, S. A., DEXTER, A. R.; ALSTON, A. M. Penetration of very strong soils by seedling roots of different plant species. Plant and Soil, The Hague, v. 135, n. 1, p. 31-41, 1991.

MEDRI, P. S.; FERRACIN, T. P.; SILVA, J. T.; TOREZAN, J. M. D.; PIMENTA, J. A.; BIANCHINI, E. Comparação de parâmetros bióticos e abióticos entre fragmento de floresta secundária e reflorestamento de Araucaria angustifolia (Bertol.) O. Kuntze. Semina: Ciências Biológicas e da Saúde, Londrina, v. 30, n. 2, p. 185-194, jul/dez. 2009.

MEIRA-NETO, J. A. A.; MARTINS, F. R.; SOUZA, A. L. de. Influência da cobertura e do solo na composição florística do sub-bosque em uma floresta estacional semidecidual em Viçosa, MG, Brasil. Acta Botânica Brasílica, Porto Alegre, v. 19, n. 3, p. 473-486, 2004.

MOLOFSKY, J.; AUGSPURGER, C. K. The effect of leaf litter on early seedling establishment in a tropical forest. Ecology, Washington, v. 73, n. 11, p. 68-77, 1992.

MONTTGOMERY, R. A.; CHAZDON, R. L. Light gradient partitioning by tropical tree seedlings in the absence of canopy gaps. Oecologia, Berlin, v. 131, n. 22, p. 165-174, 2002.

OSMASTON, F. C. The Management of Forests. London: George, Allen and Unwin, 1968. 384 p.

PARTHASARATHY, N. Tree diversity and distribution in undisturbed and human-impacted sites of tropical wet evergreen forest in southern Western Ghats, India. Biodiversity and Conservation, London, v. 8, n. 4, p. 1365-1381. 1999. 
PEREIRA-SILVA, E. F. L. Alterações temporais na distribuição dos diâmetros de espécies arbóreas. 2004. Tese (Mestrado em Biologia Vegetal) - Universidade de Campinas, São Paulo, 2004.

POGGIANI, F.; ZAMBERLAN, E.; MONTEIRO JUNIOR, E.; GAVA, I. C. Quantificação da deposição de folhedo em talhões experimentais de Pinus taeda, Eucalyptus viminalis e Mimosa scabrella plantados em uma área degradada pela mineração do xisto betuminoso. Instituto de Pesquisas e Estudos Florestais, Piracicaba, v. 37, n. x, p. 21-29, 1987.

POWERS, J. S.; HAGGAR, J. P.; FISHER, R. F. The effect of overstory composition on understory woody regeneration and species richness in 7-year-old plantations in Costa Rica. Forest Ecology and Management, Amsterdam, v. 99, n. 1/2, p. 43-54, 1997.

PRITCHETT, W. L. Properties and management of forest soils. New York: J. Wiley, 1979. 500 p.

REICH, P. B. Phenology of tropical forests: patterns, causes, and consequences. Cannadian Journal of Botany, Ottawa, v. 73, n. 1, p. 164-174, 1995.

RIGATTO, P. A.; DEDECK, R. A.; MATTOS, J. L. M. Influência dos atributos do solo sobre a produtividade de Pinus taeda. Revista Árvore, Viçosa, v. 29, n. 5, p. 701709, 2005.

RUBIN,B.D.;MANION,P.D.;FABER-LANGENDOEN, D. Diameter distributions and structural sustainability in forests. Forest Ecology and Management, v. 222, n. 2006, p. 427-438, 2005.

RUIZ-JAEN, M. C.; AIDE, T. M. Restoration success: How is it being measured? Restoration Ecology, Malden, v. 13, n. 3, p. 569-577, 2005.

SCHUMACHER, M. V.; POGGIANI, F. Caracterização microclimática no interior dos talhões de Eucalyptus camaldulensis Dehnh, Eucalyptus grandis Hill ex Maiden E Eucalyptus torelliana F. Muell, localizados em Anhembi, SP. Ciência Florestal, Santa Maria, v. 3, n. 1, p. 9-20, 1993

SCOLFORO, J. R. S.; PULZ, F. A.; MELLO, J. M. Modelagem da produção, idade das floresta nativas, distribuição espacial das espécies e a análise estrutural. In: SCOLFORO, J. R. S. (Org.). Manejo Florestal.
Lavras, UFLA/FAEPE, 1998. p. 189-245.

SIEGEL, S. Estatística não paramétrica para ciência do comportamento. Rio de Janeiro: McGraw - Hill, 1975.

SILVA JUNIOR, M. C.; SCARANO, F. R.; SOUZA, F. C. Regeneration of an Atlantic forest formation in the understorey of a Eucalyptus grandis plantation in south eastern Brazil. Journal of Tropical Ecology, Cambridge, v. 11, part. 1, p. 147-152, 1995.

SOIL SURVEY DIVISION STAFF. Department of Agriculture. Soil survey manual. Handbook Soil Conservation Service. U.S, 1993.

SPURR, S. H. Forest ecology. New York: Ronald Press Company, 1964. $352 \mathrm{p}$.

SUGANUMA, M. S. Enriquecimento de espécies vegetais em um reflorestamento utilizando serapilheira e solo de florestas maduras. 2005. Monografia (Bacharelado em Ciências Biológicas) - Universidade Estadual de Londrina, Londrina, 2005.

SUGANUMA, M. S. Avaliação de sucesso da restauração florestal baseada em estrutura florestal e processos do ecossistema. 2008. Tese (Mestrado em Ciências Biológicas) - Universidade Estadual de Londrina, Londrina, 2008.

THÉBAUD, C.; STRASBERG, D. Plant dispersal in fragmented landscapes: a field study of wood colonization in rainforest remnants of the Mascarene Archipelago. In: LAURANCE, W. F.; BIERREGAARD, Jr. (Ed.). Tropical Forest Remnants: Ecology, Management, and Conservation of Fragmented Communities. Chicago: University of Chicago Press, 1997. p. 321-332.

TREWARTHA, G. T.; HORN, L. H. An introduction to climate. 5. ed. New York: McGraw-Hill, 1980. 416 p.

TRICHON, V.; WALTER, J. M. N.; LAUMONIER, Y. Identifying spatial patterns in the tropical rain forest structure using hemispherical photographs. Plant Ecology, Dordrecht, v. 137, n. 2, p. 227-244, 1998.

UHL, C.; MURPHY, P. G. Composition, structure, and regeneration of a "tierra firme" forest in the Amazon Basin of Venezuela. Tropical Ecology, Cambridge, v. 22, n. 2, p. 219-237, 1981. 
VÁZQUEZ-YANEZ, C.; OROSCO-SEGOVIA, WIRTH, R.; WEBER, B.; RYEL, R. J. Spatial and A. Ecological significance of light controlled seed temporal variability of canopy structure in a tropical germination in two contrasting tropical habitats. moist forest. Acta Oecologica, Paris, v. 22, p. 235-244, Oecologia, Berlin, v. 83, n. 2, p. 171-175, 1990. 2001.

WEBB, L. S.; TRACEY, J. G.; WILlinS, W. T. ZAR, J. H. Biostatistical analysis. 2. ed. New Jersey: Regeneration and pattern is the subtropical rain forest. Journal of Ecology, Oxford, v. 60, n. 3, p. 675-695, 1972.

Prentice Hall, 1984.

Recebido em 18 de setembro de 2008 - Received on September 18, 2008. Aceito em 2 de março de 2009 - Accepted on March 2, 2009. 